\title{
Some Physical and Mechanical Properties of
}

\section{Fennel Seed (Foeniculum vulgare)}

\author{
Hojat Ahmadi \\ Department of Agricultural Machinery Engineering, Faculty of Biosystems Engineering \\ University of Tehran, P.O. Box 4111, Karaj 31587-77871, Iran \\ Kaveh Mollazade(Corresponding author) \\ Department of Agricultural Machinery Engineering, Faculty of Biosystems Engineering \\ University of Tehran, P.O. Box 4111, Karaj 31587-77871, Iran \\ Tel: 98-918-972-0639 E-mail: kaveh.mollazade@gmail.com,mollazade@ut.ac.ir
}

Jalal Khorshidi

Depatment of Horticulture, Faculty of Horticulture and Plant Protection

University of Tehran, Karaj, Iran

Seyed Saeid Mohtasebi

Department of Agricultural Machinery Engineering, Faculty of Biosystems Engineering

University of Tehran, P.O. Box 4111, Karaj 31587-77871, Iran

Ali Rajabipour

Department of Agricultural Machinery Engineering, Faculty of Biosystems Engineering, University of Tehran, P.O.

Box 4111, Karaj 31587-77871, Iran

The research is financed by Faculty of Biosystems Engineering, University of Tehran, Karaj, Iran.

\begin{abstract}
Determination of physical and mechanical properties of seeds and agricultural products is important in the design of harvesting, handling, and processing equipment. Some physical and mechanical properties of fennel seed were determined as a function of moisture content in the range of $7.78-21.67 \%$ d.b. The average length, width and thickness were $58.87,18.96$ and $15.64 \mathrm{~mm}$, at a moisture content of $7.78 \%$ d.b., respectively. In the moisture range from $7.78 \%$ to $21.67 \%$ d.b., studies on rewetted fennel seed showed that the thousand seed weight increased from 5.5 to $9.2 \mathrm{~g}$, the porosity from $55.91 \%$ to $62.21 \%$, the static and dynamic angle of repose from 37.6 to 46.6 and 41 to 53.3 , respectively, the coefficient of friction on glass, plywood, and galvanized iron sheet surfaces from 0.55 to $0.74,0.45$ to 0.63 , and 0.43 to 0.66 , respectively, and deformation on width section increased from 1.68 to $1.86 \mathrm{~mm}$. The bulk density decreased from 413.51 to $352.39 \mathrm{~kg} \mathrm{~m}-3$ and rupture force on both seed length and width sections decreased from 198.93 to 78.68 $\mathrm{N}$, and 600.65 to $186.44 \mathrm{~N}$, respectively, with moisture content in the moisture range of 7.78 to $21.67 \%$ d.b. But there was not regular trend for sphericity, true density, and deformation on length section with increasing the moisture content.
\end{abstract}

Keywords: Angle of repose, Density, Rupture force, Medical plant seed, Moisture content, Porosity

\section{Introduction}

In the world today, the traditional food, forage and fiber crops are not the only plants of key agricultural and trade significance, but they also include plants whose secondary metabolites are valued for their characteristic aromatic or 
therapeutic attributes, or as main natural inputs to the proliferating perfumery and chemical industries. Fennel (Foeniculum vulgare) is a plant of the Apiaceae (Umbelliferae) family largely used to impart flavor to a number of foods, such as soup, sauces, pickles, breads, cakes, etc. It is indigenous to the Mediterranean and is cultivated in England, Germany, China, Iran, Vietnam and South America. Diuretic, analgesic and antipyretic activity has also been found in the fennel seed as well as antioxidant activity. The most frequently investigated was the essential oil which showed antioxidant, antimicrobial and hepatoprotective activity (Lucinewton et al., 2005). Present world market of fennel seed is around US\$ 80 million. Worth of Iran export of this product is about US\$10 million (Masood et al., 2004).

In order to design equipment for the handling, conveying, separation, drying, aeration, storing and processing of fennel seeds, it is necessary to determine their physical and mechanical properties as a function of moisture content. The properties of different types of grains and seeds have been determined by other researchers such as Singh and Goswami (1966) for cumin seed; Shepherd and Bhardwaj (1986) for pigeon pea; Dutta et al. (1988) for gram seed; Oloso and Clarke (1993) for cashew nuts; Ougt (1998) for white Lupin; Baryeh (2002) for millet; Ogunjimi et al. (2002) for locust bean seed; Amin et al. (2004) and carman (1996) for lentil seed; Coskun et al. (2006) for sweet corn seed; and Cetin (2007) for barbunia bean.

However, no published work seems to have been carried out on the physical and mechanical properties of fennel seed and their relationship with moisture content. Hence, this study was conducted to investigate some moisture dependent physical and mechanical properties of fennel seed namely: size, thousand seed mass, sphericity, true density, bulk density, porosity, static coefficient of friction against different materials, angle of static and dynamic repose, and cracking force at safe storage moisture content.

\section{Materials and methods}

The dry seeds of fennel were used for all the experiments in this study (see Figure 1). The seeds were cleaned manually to remove all foreign matter such as dust, dirt, stones and chaff as well as immature and broken seeds. The initial moisture content of the seeds was determined by oven drying at $105 \pm 1 \mathrm{oC}$ for $24 \mathrm{~h}$ (Ozarslan, 2002). The initial moisture content of the seeds was $7.78 \%$ d.b. The samples of the desired moisture contents were prepared by adding the amount of distilled water as calculated from the following relation (Sacilik et al. 2003):

$$
Q=\frac{W_{i}\left(M_{f}-M_{i}\right)}{\left(100-M_{f}\right)}
$$

where $\mathrm{W}_{\mathrm{i}}$, is the initial mass of sample in $\mathrm{kg} ; \mathrm{M}_{\mathrm{i}}$, is the initial moisture content of sample in $\%$ d.b.; and $\mathrm{M}_{\mathrm{f}}$, is the final moisture content of sample in $\%$ d.b.

The samples were then poured into separate polyethylene bags and the bags sealed tightly. The samples were kept at 5o $\mathrm{C}$ in a refrigerator for a week to enable the moisture to distribute uniformly throughout the sample. Before starting a test, the required quantity of the seed was taken out of the refrigerator and allowed to equilibrate to the room temperature for about $2 \mathrm{~h}$ (Singh and Goswami, 1996; Coskun et al. 2006). All the physical and mechanical properties of the seeds were determined at five moisture contents in the range of $7.78-21.67 \%$ d.b. with four replications at each moisture content.

The following methods were used in the determination of some physical and mechanical properties of fennel seed.

\subsection{Size and shape}

A vernire caliper was used to measure the axial dimensions of randomly selected 100 seeds; length, width, and thickness. From the average of axial dimensions the geometric mean diameter $\mathrm{D}_{\mathrm{g}}$ in $\mathrm{mm}$ was determined by using the following formula (Joshi et al., 1993):

$$
D_{p}=(a b c)^{1 / 3}
$$

where: $\mathrm{a}$, the length is the dimension along the longest axis in $\mathrm{mm}$; $\mathrm{b}$, the width is the dimension along the longest axis perpendicular to a in $\mathrm{mm}$; and $\mathrm{c}$, the thickness, is the dimension along the longest axis perpendicular to both $\mathrm{a}$ and $\mathrm{b}$ in $\mathrm{mm}$.

The sphericity was determined using (Mohsenin, 1970):

\subsection{Thousand seed weight}

$$
\psi=\frac{(a b c)^{1 / 3}}{a}
$$

Thousand seed weight (TSW) was measured by counting 100 seeds and weighing them in an electronic balance to an accuracy of $0.001 \mathrm{~g}$ and then multiplied by 10 to give mass of 1000 seeds.

\subsection{Bulk and true densities}

The bulk density was determined by filling an empty $250 \mathrm{ml}$ graduated cylinder with the seed and weighed (Mohsenin, 
1970). The weight of the seeds was obtained by subtracting the weight of the cylinder from the weight of the cylinder and seed. To achieve uniformity in bulk density the graduated cylinder was tapped 10 times for the seeds to consolidate. The volume occupied was then noted. The process was replicated four times and the bulk density for each replication was calculated from the following relation:

$$
\rho_{b}=\frac{W_{s}}{V_{s}}
$$

where: the $\rho_{\mathrm{b}}$ is the bulk density in $\mathrm{kg} \mathrm{m}^{-3}$; Ws is the weight of the sample in $\mathrm{kg}$; and $\mathrm{V}_{\mathrm{s}}$ is the volume occupied by the sample in $\mathrm{m}^{3}$.

The true density was defined as the ratio between the mass of fennel seeds and the true volume of the seeds, and determined using the toluene (C7H8) displacement method. Toluene was used instead of water because it is absorbed by seeds to a lesser extent. The volume of toluene displaced was found by immersing a weighted quantity of fennel seeds in the measured toluene (Tavakkoli et al. 2006).

\subsection{Porosity}

This was calculated from the values of bulk and true densities using the following relationship (Mohsenin, 1970):

where $\rho_{\mathrm{t}}$ is true density and $\varepsilon$ is the porosity.

$$
\varepsilon=\left(1-\frac{\rho_{b}}{\rho_{t}}\right) \times 100
$$

\subsection{Angle of repose}

The static angle of repose $\left(\theta_{\mathrm{s}}\right)$ was determined by using the apparatus in Figure 2 consisting of plywood box of $140 * 160 * 35 \mathrm{~cm}$ and two plates: fixed and adjustable. The box was filled with the sample and then the adjustable plate was inclined gradually allowing the kernels to follow and assume a natural slope (Tabatabaeefar, 2003; Heidabeigi et al., 2009). The dynamic angle of repose $\left(\theta_{\mathrm{d}}\right)$ was determined using a hollow cylinder and then trigonometry rules (Mohsenin, 1970).

\subsection{Coefficient of friction}

Coefficient of static friction of fennel seed on three surface including wood, galvanized steel, and glass was determined. In order to achieving this end, fennel seeds were put on the surface with changeable slip. When seeds were started to motion, tangent of slip angle was showed the coefficient of friction (Heidabeigi et al., 2009).

\subsection{Mechanical properties}

Rupture Strength for fennel seed was determined from forces acting on the two sections length and width with speed of load $5 \mathrm{~mm} / \mathrm{min}$ (see Figure 3). For width section, samples were prepared as a cubic shape. Method of test was putting the seed on desired section and selecting speed of loading and after that applying force till seed fractured. Instron Universal Testing Machine (Model Santam STM-5), that is equipped with a $25 \mathrm{~kg}$ compression load cell and integrator, was used for this test. The measurement accuracy was $0.001 \mathrm{~N}$ in force and $0.001 \mathrm{~mm}$ in deformation (Mohsenin, 1970; Ahmadi et al. 2009).

The individual seed was loaded between two parallel plates of the machine and compressed at the present condition until rupture occurred as is denoted by a bio-yield point in the force-deformation curve. Once the bio-yield was detected, the loading was stopped. The mechanical properties of fennel seed were expressed in terms of rupture required for initial rupture.

\subsection{Statistical analysis}

The results gained were subjected to statistical analysis using SPSS 13 (SPSS Inc., USA) software and analysis of regression using Microsoft Excel 2003 (Microsoft Corp., USA).

\section{Results and discussion}

\subsection{Seed Moisture Content}

The initial moisture content of the seed was found to be $7.78 \pm 0.31 \%$ d.b. The four other moisture levels obtained after conditioning the seeds were $10.91 \pm 0.53,14.83 \pm 0.72,17.76 \pm 1.02$, and $21.67 \pm 0.34 \%$ d.b., respectively. The investigations were carried out at the above moisture levels to determine the effect of moisture content on the physical and mechanical properties of fennel seed.

\subsection{Size and shape}

The variation of the seed length, width, thickness and geometric mean diameter variation with seed moisture content is displayed in Table 1. The table shows that the three axial dimensions increased significantly $(\mathrm{P}<0.05)$ with moisture content in the moisture range of 7.78 to $21.67 \%$ d.b. The Length increased from 58.87 to 69.04 mm, the width from 
18.96 to $21.96 \mathrm{~mm}$, and the thickness from 15.64 to $18.47 \mathrm{~mm}$. Also the geometric mean diameter increased with increase in moisture content. These could be of important consideration in the theoretical determination of the seed volume at different moisture contents.

Similar results of increase are reported by Tavakkoli et al. (2009) for soybean grains and Al-Mahasneh and Rababah (2007) for green wheat.

\subsection{Sphericity}

The sphericity was found to increase from 43.91 at the moisture content of $10.97 \%$ d.b. to a maximum value of 45.1 at the moisture content of $17.76 \%$ d.b., after which it decreased with further increase in moisture content. The effect of moisture content on the seed sphericity is presented in Figure 4. The relationship existing between sphericity and moisture content was found to be parabolic and can be expressed using the following equation with a coefficient of determination $\mathrm{R}^{2}=0.63$ :

$$
\psi=-0.0194 M^{2}+0.5969 M+40.331
$$

Former researches showed that sphericity could be affected by moisture content in different ways. A decrease in the sphericity with increase in moisture content was observed for pigeon pea (Baryeh and Mangope, 2002). Cuskun et al. (2006) showed that sphericity of sweet corn seed is inceased linearly by moisture content.

\subsection{Thousand seed weight}

Figure 5 shows the thousand seed weight variation with seed moisture content $(\mathrm{P}<0.05)$. The Figure indicates that the thousand seed mass increases linearly with increase in seed moisture content. The variation can be expressed mathematically as follows with a coefficient of determination $\mathrm{R}^{2}=0.96$ :

$$
T S W=0.2498 M+3.8355
$$

\subsection{Bulk and true densities}

The variation of bulk density and true density with seed moisture content is depicted in Figure 6 . This shows that the bulk density of seed decreased from 413.51 to $352.39 \mathrm{~kg} \mathrm{~m}^{-3}$ in the above moisture range $(\mathrm{P}<0.05)$. The relationship existing between bulk density and the seed moisture content can be expressed with the following equation:

$$
\rho_{b}=-15.621 M+431.82, \quad \mathrm{R}^{2}=0.97
$$

True density decreased from 937.98 to $889.08 \mathrm{~kg} \mathrm{~m}^{-3}$ as the moisture content increased from 7.78 to $14.83 \%$ d.b. and increased to $932.62 \mathrm{~kg} \mathrm{~m}^{-3}$ as the moisture content increased to $21.67 \%$ d.b. The relationship existing between true density and moisture content was found to be parabolic and can be represented by the following equation:

$$
\rho_{t}=9.8021 M^{2}-62.266 M+996.07, \quad \mathrm{R}^{2}=0.82
$$

Carman (1996), Gupta and Das (1998), and Visvanathan et al. (1996) found the bulk density of lentil seeds, sunflower seeds, neem nuts to decrease as the seed moisture content increases. Increase of true density as the seed moisture content increases has been found by Gupta and Das (1998) for sunflower seeds, Aviara et al. (1999) for guna seeds, Chandrasekar and Visvanathan (1999) for coffee.

\subsection{Porosity}

Figure 7 shows the porosity variation with seed moisture content. The Figure reveals that the porosity increases with increase in seed moisture content from $55.91 \%$ porosity at $7.78 \%$ d.b. seed moisture content to $62.21 \%$ porosity at $21.67 \%$ seed moisture content. The relationship existing between porosity and seed moisture content was found to be linear and can be expressed using the following equation with a coefficient of determination $\mathrm{R}^{2}=0.87$ :

$$
\varepsilon=0.4418 M+51.574
$$

An increase in porosity with moisture content were reported for chickpea seeds (Konak et al., 2002), and green gram (Nimkar and Chattopadhyay, 2001).

\subsection{Angle of repose}

Figure 8 shows the variation of both the static and dynamic angle of repose with seed moisture content. From this Figure, it can be seen that both the static and dynamic angle of repose increased linearly $(\mathrm{P}<0.05)$ in the moisture range of 7.78 to $21.67 \%$ d.b. from 37.6 to 46.6 and from 41 to 53, respectively. This shows that the amount of dynamic angle of repose was higher than static angle of repose at each moisture content. The relationship existing between the static and dynamic angle of repose and moisture content can be expressed using the following equations:

$$
\begin{aligned}
\theta_{s} & =2.26 M+35.5, & \mathrm{R}^{2}=0.99 \\
\theta_{d} & =3.19 M+37.93, & \mathrm{R}^{2}=0.95
\end{aligned}
$$


These results were similar to those reported by Garnayak et al. (2008) for jatropha seed and Pradhan et al. (2008) for karanja kernel.

\subsection{Coefficient of friction}

The coefficient of friction of fennel seed increased linearly $(\mathrm{P}<0.05)$ for glass surface and logarithmically for both Plywood and galvanized iron sheet surfaces with moisture content and varied with structural surface in the moisture range of 7.78 to $21.67 \%$ d.b. (see Figure 9). The maximum value of 0.74 was obtained on the surface of glass and the minimum value of 0.43 was on the surface of galvanized iron sheet. The relationship existing between the coefficient of friction and moisture content can be expressed for different structural surfaces using the following equations:

$$
\begin{gathered}
f_{g}=0.0124 M+0.4504 \\
f_{w}=0.1723 \operatorname{Ln}(M)+0.1129 \\
f_{\text {gis }}=0.215 \operatorname{Ln}(M)+0.0171
\end{gathered}
$$

with coefficients of determination $\mathrm{R}^{2}$ of $0.93,0.94$, and 0.92 , respectively, where $\mathrm{fg}$, fw, and fgis are the static coefficients of friction of seed on glass, Plywood, and galvanized iron sheet, respectively.

Similar findings were reported for millet (Baryeh, 2002), pumpkin seeds (Joshi et al., 1993), and karingda seeds (Suthar and Das, 1996).

\subsection{Rupture strength}

Effect of seed moisture content and force axis on the rupture force and deformation is shown in Table 2. The table shows that the rupture force on both the seed length and width sections decreased with moisture content in the moisture range of 7.78 to $21.67 \%$ d.b. Deformation on the seed length section increased in the moisture range of 10.91 to $21.67 \%$ d.b. But there was not regular trend for deformation on the seed width section with increasing the moisture content. The relationship existing between the both rupture force and deformation with moisture content can be expressed using the following equations:

$$
\begin{array}{ll}
F_{L}=-404.55 \operatorname{Ln}(M)+1406.9, & \mathrm{R}^{2}=0.98 \\
F_{w}=-138.19 \operatorname{Ln}(M)+491.61, & \mathrm{R}^{2}=0.89 \\
D_{L}=0.0015 M^{2}-0.0326 M+1.861, & \mathrm{R}^{2}=0.88 \\
D_{W}=0.0021 M^{2}-0.0725 M+1.707, & \mathrm{R}^{2}=0.91
\end{array}
$$

Where $F_{l}, F_{w}, D_{l}$, and $D_{w}$ are rupture force on seed length section, rupture force on seed width section, deformation on seed length section, and deformation on seed width section, respectively.

Tavakoli et al. (2009) for soybean grain reported that the rupture force decreased whit increase the moisture content.

\section{Conclusions}

Some physical and mechanical properties of fennel seed are presented in this research and it can be concluded that:

(1) In the moisture range of 6.78 to $21.67 \%$ d.b. the length, width, thickness, and geometric mean diameter of the fennel seed increased from 58.87-64.09, 18.96-21.96, 15.64-18.87, and 25.95-30.36 mm, respectively.

(2) Thousand seed weight, porosity, static and dynamic angle of repose, and coefficient of friction on glass surface increased linearly, while bulk density reduced linearly and coefficient of friction on both Plywood and galvanized iron sheet surfaces increased logarithmically.

(3) There was a parabolic mathematical equation for sphericity, true density, and deformation on both seed length and width sections with changes of moisture content.

(4). Rupture force on both seed length and width sections decreased logarithmically with moisture content in the above moisture range.

(5) Results of this research showed that the porosity affects the resistance to airflow through bulk solids. The static coefficient of friction and angle of repose is necessary to design conveying machine and hopers used in planter machines. When seeds are ground in mills, the rupture force must be known in order to achieve desirable properties without unnecessary expenditure of energy.

\section{References}

Ahmadi, H., Fathollahzadeh, H., \& Mobli, H. (2009). Post harvest physical and mechanical properties of apricot fruits, pits and kernels (C.V. Sonnati Salmas) cultivated in Iran. PakJ Nut, 8(3), 264-268.

Al-Mahasneh., M. A., \& Rababah, T. M. (2007). Effect of moisture content on some physical properties of green wheat. J Food Eng, 79, 1467-1473. 
Amin, M. N., Hossain, M. A., \& Roy, K. C. (2004). Effects of moisture content on some physical properties of lentil seeds. J Food Eng, 65(1), 83-87.

Aviara, N. A., Gwandzang, M I., \& Haque M. A. (1999). Physical properties of guna seeds. J Agr Eng Res, 73, 105-111. Baryeh, E. A. (2002). Physical properties of millet. J Food Eng, 51:39-46.

Baryeh, E. A., \& Mangope, B. K. (2002). Some physical properties of QP-38 variety pigeon pea. J Food Eng, 56, 5965.

Carman, K. (1996). Some physical properties of lentil seeds. J Agr Eng Res, 63(2), 87-92.

Cetin, M. (2007). Physical properties of barbunia bean (Phaseolus vulgaris L. cv. 'Barbunia') seed. J Food Eng, 80, 353-358.

Chandrasekar, V., \& Visvanathan, R. (1999). Physical and thermal properties of coffee. J Agr Eng Res, 73, 227-234.

Coskun, M. B., Yalcin, I., \& Ozarslan, C. (2006). Physical properties of sweet corn seed (Zea mays saccharata sturt). $J$ Food Eng, 74, 523-528.

Dutta, S. K., Nema, V. K., \& Bhardwaj, R. K. (1988). Physical properties of gram. J Agr Eng Res, 39, 259-268.

Garnayak, D. K., Pradhan, R. C., Naik S. N., \& Bhatnagar, N. (2008). Moisture-dependent physical properties of Jatropha seed (Jatropha curcas L.). Ind Crop Product, 27, 123-129.

Gupta, R. K., \& Das S. K. (1998). Friction coefficients of sunflower seed and kernel on various structural surfaces. $J$ Agr Eng Res, 71, 175-180.

Heidarbeigi, K., Ahmadi, H., Khaeiralipour, K., \& Tabatabaeefar, A. (2009). Some physical and mechanical properties of khinkuk. Pak J Nut, 8(1), 74-77.

Joshi, D. C., Das, S. K., \& Mukherjiee, R. K. (1993). Physical properties of pumpkin seeds. J Agr Eng Res, 54(3), 19-229.

Konak, M., Carman k., \& Aydin. C. (2002). Physical properties of chickpea seeds. Biosys Eng, 82, (1): 73-78.

Kheiralipour, K., Karimi, M., Tabatabaeefar, A., Naderi, M., Khoubakht, G., \& Heidarbeigi, K. (2008). Moisture-dependent physical properties of wheat (Triticum aestivum L.). J Agr Tech., 4(1), 53-64.

Lucinewton, S., Raul, N., Carvalho, J., Mirian, B., Lin, C., \& Angela, A. (2005). Supercritical fluid extraction from fennel (Foeniculum vulgare): global yield, composition and kinetic data. J Supercrit Fluid, 35, 212-219.

Masood, A., Syed Asghar, H., Mohammad Z., \& Abdur, R. (2004). Effect of different sowing season and row spacing on seed production of fennel (Foeniculum vulgare). J Bio Scie, 7(7), 1144-1147.

Mohsenin, N. N. (1970). Physical properties of plant and animal materials. New York: Gordon and Breach Science.

Nimkar, P. M., \& Chattopadhyay, P. K. (2001). Some physical properties of green gram. J Agri Eng Res, 80(2), 183-189.

Ogunjimi, L. A. O., Aviara, N. A., \& Aregbesola, O. A. (2002). Some engineering properties of locust bean seed. J Food Eng, 55(2), 95-99.

Oloso, A. O., \& Clark, B. (1993). Some aspects of strength properties of cashew nuts. J Agr Eng Res, 55, $27-43$.

Ougt, H. (1998). Some physical properties of white lupin. J Agr Eng Res, 69, 273-277.

Ozarslan, C. (2002). Physical properties of cotton seed. Bio Eng, 83(2), 169-174.

Pradhan, R. C., Naik, S. N., Bhatnagar N., \& Swain, S. K. (2008). Moisture-dependent physical properties of Karanja (Pongamia pinnata) kernel. Ind Crop Product. 28(2), 155-161.

Sacilik, K., Ozturk, R., \& Keskin, R. (2003). Some physical properties of hemp seed. Bio Eng, 86(2), 191-198.

Singh, K. K, \&Goswami, T. K. (1996). Physical properties of cumin seed. J Agr Eng Res, 64:93-98.

Shepherd, H., \& Bhardwaj, R. K. (1986). Moisture-dependent physical properties of pigeon pea. J agr Eng Res, 35(4), $27-234$.

Suthar, S. H., \& Das, S. K. (1996). Some physical properties of karingda seeds. J Agr Eng Res, 65, 15-22.

Tabatabaeefar, A. (2003). Moiture-dependent physical properties of wheat. Inter Agrophysics, 17, 207-211.

Tavakoli, H., Rajabipour, A., \& Mohtasebi, S. S. (2009). Moisture-dependent some engineering properties of soybean grains. Agr Eng Inter: the CIGR. Ejournal, Manuscript 1110, Vol. XI.

Visvanathan, R., Palanisamy, P. T., Gothandapani V., \& Sreenarayanan V. V. (1996). Physical properties of neem nuts. $J$ Agr Eng Res, 63, 19-26. 
Table 1. Variation of principal dimensions with seed moisture content

\begin{tabular}{|l|l|l|l|l|}
\hline $\begin{array}{c}\text { Seed moisture } \\
\text { content, \% d.b. }\end{array}$ & \multicolumn{1}{|c|}{ Length, mm } & \multicolumn{1}{|c|}{ Width, mm } & $\begin{array}{c}\text { Thickness, } \\
\mathrm{mm}\end{array}$ & \multicolumn{1}{|c|}{$\begin{array}{c}\text { Geometric mean } \\
\text { diameter, mm }\end{array}$} \\
\hline 7.78 & $58.87(0.8)^{*}$ & $18.96(0.17)$ & $15.64(0.2)$ & 25.95 \\
\hline 10.91 & $59.94(0.56)$ & $19.29(0.14)$ & $15.86(0.11)$ & 26.37 \\
\hline 14.83 & $64.09(0.63)$ & $21.19(0.22)$ & $17.71(0.21)$ & 28.86 \\
\hline 17.76 & $65.3(0.63)$ & $21.37(0.17)$ & $18.31(0.16)$ & 29.45 \\
\hline 21.67 & $69.04(0.74)$ & $21.96(0.23)$ & $18.47(0.15)$ & 30.36 \\
\hline
\end{tabular}

* Values in parentheses are standard deviation

Table 2. Effect of seed moisture content and force axis on rupture force and deformation

\begin{tabular}{|l|l|l|l|l|l|l|}
\hline \multirow{2}{*}{\multicolumn{2}{|c|}{}} & \multicolumn{5}{c|}{ Seed moisture content, \%d.b. } \\
\cline { 3 - 7 } & \multicolumn{1}{|c|}{7.78} & 10.91 & 14.83 & 17.76 & 21.67 \\
\hline \multirow{2}{*}{$\begin{array}{l}\text { Rupture } \\
\text { force, N }\end{array}$} & Length & $600.25(8.41)$ & $417.43(9.63)$ & $294.26(7.56)$ & $239.48(5.9)$ & $186.44(4.9)$ \\
\cline { 2 - 7 } & Width & $198.83(13.97)^{*}$ & $189.03(17.98)$ & $99.39(8.04)$ & $82.97(13.21)$ & $78.68(3.43)$ \\
\hline $\begin{array}{l}\text { Deformation, } \\
\text { mm }\end{array}$ & Length & $1.71(0.26)$ & $1.68(0.11)$ & $1.69(0.52)$ & $1.81(0.9)$ & $1.86(0.3)$ \\
\cline { 2 - 7 } & Width & $1.28(0.11)$ & $1.15(0.14)$ & $1.09(0.47)$ & $1.1(0.51)$ & $1.12(0.1)$ \\
\hline
\end{tabular}

* Values in parentheses are standard deviation

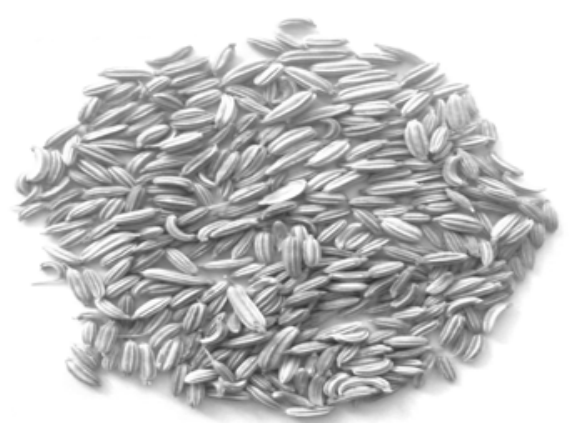

Figure 1. Fennel Seeds 


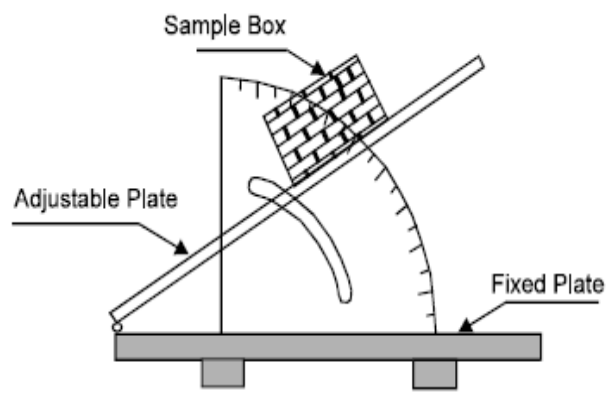

Figure 2. Apparatus to determine angle of repose

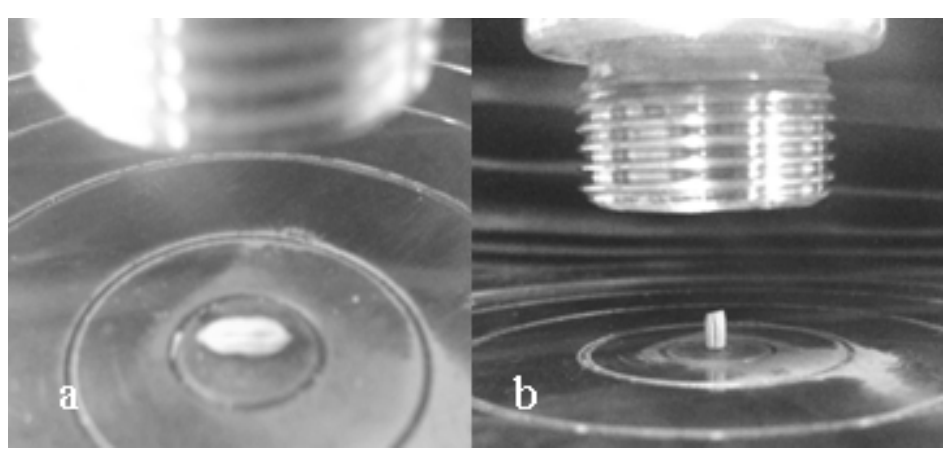

Figure 3. Rupture strength test for fennel seed

a. force acting on the seed length section $\quad$ b. force acting on the seed width section

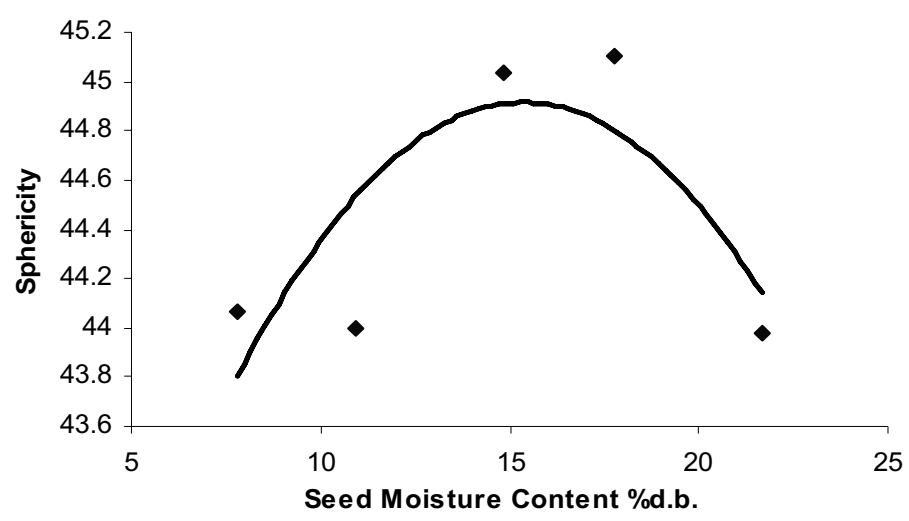

Figure 4. Variation of the sphericity of fennel seed with moisture content 


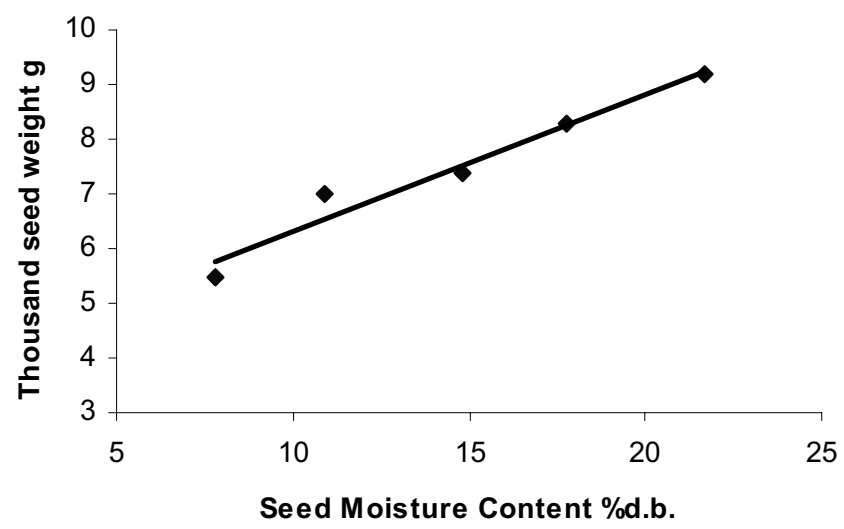

Figure 5. Effect of moisture content on the thousand seed weight

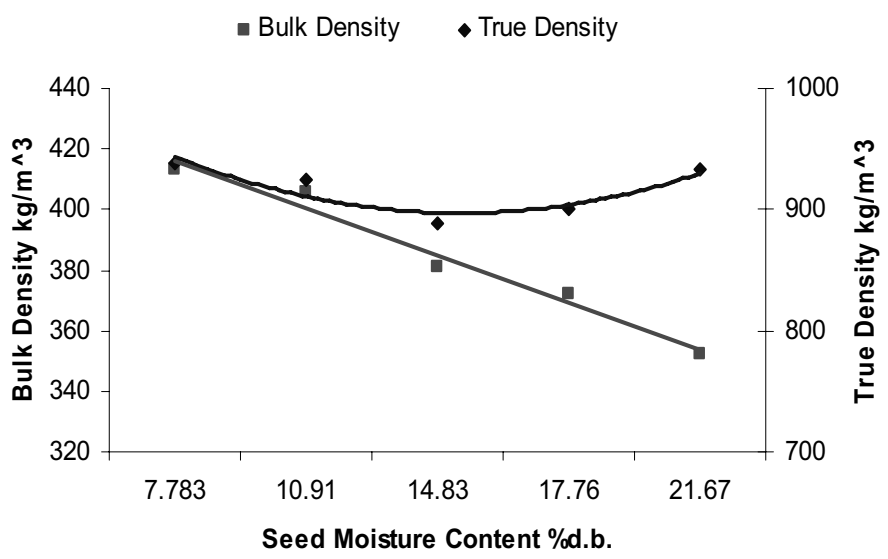

Figure 6. Bulk and true density variation with seed moisture content

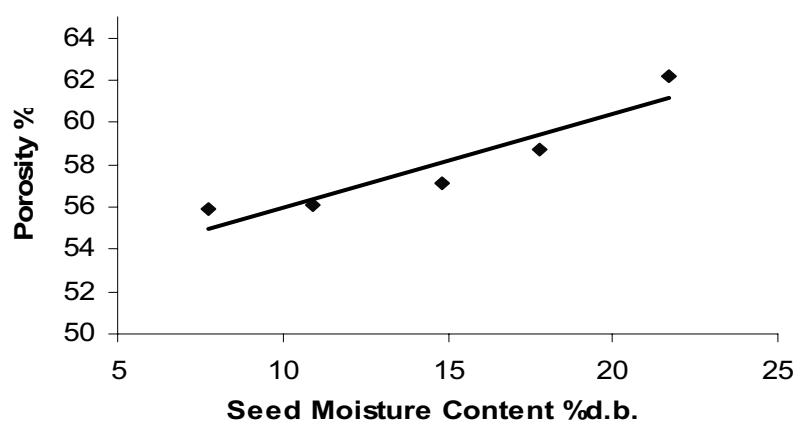

Figure 7. Effect of moisture content on the porosity 


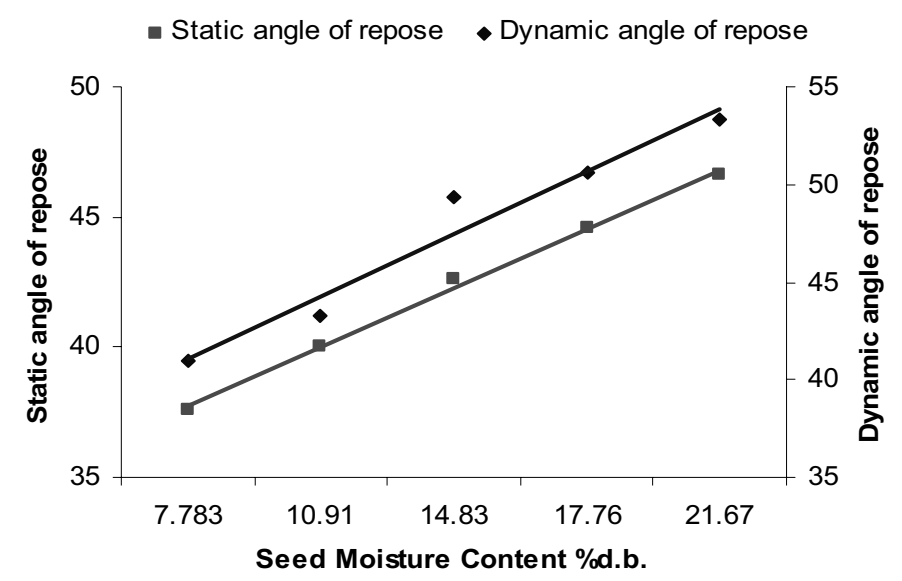

Figure 8. Static and dynamic angle of repose variation with seed moisture content

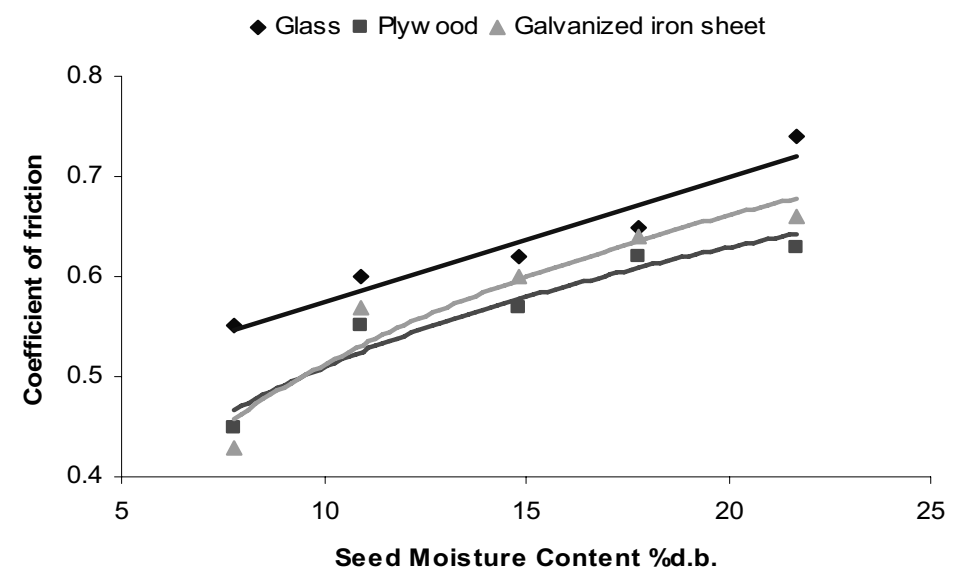

Figure 9. Coefficient of friction variation with seed moisture content 